\title{
The status of purpose, reason, and intended endpoint in the typology of complex sentences: implications for layered models of clause structure
}

\author{
JEAN-CHRISTOPHE VERSTRAETE
}

\section{Abstract}

This study argues that constructions of purpose, reason and intended endpoint have a special status in typologies of complex sentences, because they combine features of the adverbial domain and the complement domain. The feature they share with adverbial clauses is that they do not function as the object of the predicate of the main clause, but instead elaborate on its circumstances. The feature they share with complement clauses is that unlike other adverbial clauses they specify the mental state of some participant in the main clause, typically the agent. Evidence for this special status comes from two sources. On the one hand, it is shown that the recognition of a mental state relation is necessary in semantic terms, to distinguish the three constructions from semantically similar types in the adverbial domain, and to explain their exceptional behavior in terms of presupposition. On the other hand, it is also shown that the presence of such a mental state relation is crosslinguistically reflected in the formal make-up of the three construction types, specifically in the use of mood markers in the dependent clause, and in the use of conjunctions that are shared with the domain of represented speech. From a theoretical perspective, the intermediate status of constructions of purpose, reason and intended endpoint is important because it provides structural evidence for layered models of clause structure, specifically for the distinction between a description-related and an interaction-related layer of organization, and for a further subdivision of the interaction-related layer in terms of modal and illocutionary features.

\section{Introduction ${ }^{1}$}

The traditional typology of complex sentences distinguishes between three basic types of clause combining, depending on the function of one clause relative to the other (see Thompson and Longacre 1985). Complement 
clauses function as an argument of another clause, like the that-clause in (1), adverbial clauses function as an adjunct of another clause, like the when-clause in (2), and relative clauses elaborate on an NP in another clause, like the who-clause in (3).

(1) Jim firmly believed that he was Napoleon's great-great-grandson.

(2) Jim organized a big party when the DNA evidence confirmed this.

(3) The man who turned out to be a descendant of Napoleon will not visit France.

In this article, I will argue that the distinction between the categories of complement clauses and adverbial clauses is not as clear-cut as has traditionally been assumed, and I will show that this has important theoretical consequences for layered models of clause structure. Specifically, I will focus on three types of complex sentences that have traditionally been classified as adverbial, viz. purpose constructions, illustrated in (4) below, reason constructions, illustrated in (5) below, and intended endpoint constructions, illustrated in (6) below. ${ }^{2}$

(4) He left the back door open so that the plumber could get in.

(5) He set the alarm because there might be burglars in the area.

(6) He kept banging on the door until somebody opened it.

I will argue that these three construction types need to be defined in terms of features of both the adverbial domain and the complement domain. Clauses of purpose, reason and intended endpoint have traditionally have been regarded as adverbial clauses, because they provide adverbial modification of the main clause. They also have a crucial semantic feature that is typical of complement clauses, however. Many types of complement clauses describe the perspective of some participant in the main clause, as in constructions of represented speech or thought, and more generally constructions with mental state predicates. This is a feature we also find in constructions of purpose, reason and intended temporal endpoint. Just as the complement clause in (1) represents a mental state of the agent of the main clause, viz. the content of the belief that is attributed to Jim, the purpose clause in (4) represents a mental state associated with the agent of the main clause: the plumber's ability to get into the house is what is intended by the agent of the action described in the main clause. What distinguishes the three constructions in (4)-(6) from genuine complement constructions, however, is that the predicate in the main clause does not describe a mental state of the agent of the main clause. While the predicate believe in (1) explicitly describes the mental state whose content is elaborated in the dependent clause, the predicate leave open in (4) does 
not describe a mental state, and the dependent clause does not describe its content but rather provides adverbial modification.

The evidence I will adduce for the intermediate character of the purpose, reason and intended endpoint constructions is of two kinds. On the one hand, I will argue that the recognition of the mental state relation with the agent of the main clause is crucial in the semantic description of the constructions in question. I will show that the feature is needed to distinguish the three construction types from closely related constructions that are entirely in the adverbial domain, and I will show that it can also help us to elucidate their exceptional behavior in terms of presupposition. On the other hand, I will use data from a wide range of languages to show that the formal properties of the three construction types often explicitly reflect the presence of a mental state relation with the agent of the main clause. I will show that in finite instantiations of the three construction types, the dependent clause typically contains some type of mood marker to signal the presence of an 'evaluating' authority, and I will demonstrate that there are specific formal strategies to establish binding of this mood to a participant in the main clause, such as the use of conjunctions that are typical of complement constructions, especially from the domain of represented speech and thought. Although most of these formal and semantic features have been noted in passing for some of the three constructions discussed here, I will argue that taken together, they can be regarded as defining a distinct and internally coherent category of complex sentences that is intermediate between the adverbial and the complement domain.

From a theoretical perspective, the existence of such intermediate construction types is significant because of the evidence it provides for layered models of clause structure. On the one hand, the presence of a mental state relation suggests that constructions of purpose, reason and intended temporal endpoint are distinct from purely adverbial constructions in that their dependent clause incorporates an interaction-related layer of organization (usually called "interpersonal", as in Halliday 1985; Halliday and Matthiessen 2004; Hengeveld 1989, 1998), i.e., that it does not merely describe an event but also encodes a particular modal attitude with respect to this event. On the other hand, these constructions also show that it is necessary to distinguish between different subtypes of interpersonal organization within this layer, which can vary independently. Although clauses of reason, purpose and intended endpoint are different from other adverbial clauses in that they have modal organization, they are like other types of subordinate clauses - and different from main clauses - in that they do not have illocutionary organization. 
From a semantic and pragmatic perspective, such independent variation is surprising, since one would not expect marking of attitudes in constructions that do not themselves encode speech acts. It can be explained, however, in terms of the feature of agent binding, which links the modal attitude in the dependent clause to a participant of the main clause rather than to the speaker.

This article will be organized in three sections. Sections 2 and 3 will detail the semantic and formal evidence for the intermediate status of constructions of purpose, reason and intended endpoint with respect to the distinction between adverbial and complement constructions. Section 2 will focus on the semantic evidence for the presence of a mental state relation with a participant in the main clause. Section 3 will focus on the formal evidence, using a sample of twenty-eight languages to show that the formal properties of constructions of purpose, reason and intended endpoint reflect the presence of this mental state relation, and that they tend to overlap with the formal means for encoding complement constructions. Section 4, finally, will bring the formal and semantic evidence together into a unified model of the domain of adverbial and complement constructions, and it will investigate the theoretical consequences of the intermediate types for the analysis of clause structure in terms of layered models.

\section{Semantic evidence}

\subsection{Mental state relations as a distinctive feature}

In this section, I will show that the mental state relations typically found in complement constructions are also an essential semantic feature of constructions of purpose, reason and intended endpoint, traditionally regarded as belonging to the adverbial domain. Specifically, the recognition of a mental state relation between the main clause and the dependent clause is essential as a minimal semantic feature to distinguish the three types studied here from the semantically closely related types of result (versus purpose), cause (versus reason) and temporal endpoint (versus intended temporal endpoint).

The two constructions in (7) and (8) below represent semantic relations of purpose and result, respectively. What they have in common is that in both cases the event described in the main clause enables a subsequent event described in the dependent clause: the back door being left open allows the plumber to get in as in (7) and it allows the burglars to enter the house in (8). 
(7) He left the back door open so that the plumber could get in.

(8) He left the back door open, so (that) the burglars had no difficulty getting in.

What distinguishes these two closely related constructions, however, is the way this enabling relation involves the participants in the main clause, as also argued in Jones (1985) and Palmer (1987). In the purpose construction in (7), the event in the dependent clause is intended by the agent of the main clause: allowing the plumber to get in is what the agent in the main clause intends by leaving the door open. In the result construction in (8), on the other hand, there is no such relation of intention: the back door being open allows burglars to get into the house, but this is definitely not what the agent of the main clause intended by leaving it open.

A very similar semantic feature can be used to distinguish constructions of reason, illustrated in (9) below, from constructions of cause, illustrated in (10). Again, both constructions have a basic semantic core in common: in both cases the event in the dependent clause is the cause of the event in the main clause, the discovery of adultery leading Julia to kill her husband in (9) and the traffic jam leading to her late arrival in (10).

(9) Julia killed her husband because he cheated on her.

(10) Julia arrived late because she was stuck in a traffic jam.

As with the previous set of constructions, there is one single feature that distinguishes these two constructions, which can again be described in terms of the way the causal relation involves the agent of the main clause, as also argued in Lowe (1987), Bolkestein (1991), and Hengeveld (1998: 344-347). In the reason construction in (9), the event in the dependent clause is not just a cause of the event in the main clause, but it represents the personal motivation of the agent of the main clause: it is the discovery of adultery that made the agent in the main clause decide to kill her husband. In the causal construction in (10), on the other hand, there is no such involvement of the main clause's agent: the traffic jam did not make her decide to be late, but was just an accidental circumstance that resulted in her being late.

Constructions that denote a temporal endpoint, finally, show the same kind of distinction between relations that involve the agent's intentions and those that do not. Both in (11) and (12) below, the dependent clause denotes the temporal endpoint of the event described in the main clause: the reworking of the essay is terminated by the teacher's passing of the student in (11) and the ending of exam time in (12).

(11) The student reworked the essay until the teacher passed him for the course. 
(12) The student reworked the essay until time was up and he had to hand it in.

Again, however, the agent's intentions make the distinction. In (11), the event in the dependent clause is intended as a break-off point by the agent of the main clause, whose goal in reworking the essay is to be passed for the course. In (12), by contrast, the event of the dependent clause is an incidental break-off point, not in any way intended by the agent of the main clause.

If we bring these three cases together, what they show is that mental state relations are a crucial semantic feature in the description of relations of purpose, reason and intended temporal endpoint, because they serve as a minimal feature that distinguishes them from counterparts like result, cause and temporal endpoint. With purpose and intended temporal endpoint, the mental state relation is one of intentionality, where the agent intends to realize the subsequent event described in the dependent clause. With reason, by contrast, the mental state relation is one of motivation: the agent does not intend to realize a subsequent event, but uses the event described in the dependent clause to motivate his or her action described in the main clause.

\subsection{Mental state relations and presupposition}

Apart from their role as a distinctive feature described in the previous section, further evidence for the semantic relevance of mental state relations in the constructions studied here is the way they can help to explain the anomalous behavior of these constructions with respect to presupposition. Presupposition is one of the features that have been associated with adverbial subordination in the literature (Keenan 1971; Winter 1982; Levinson 1983: 181-184; Nichols 1988), but like most other attempts at identifying a general functional correlate of the domain of adverbial subordination, applying the notion of presupposition has had mixed results (see further in Verstraete 2004).

As noted in Keenan (1971), many construction types traditionally analyzed as adverbial subordinate clauses are semantically special in that they involve presupposition. This is the case, for instance, with the whenclause in (13a) below: if we negate the main clause, as in (13b), or interrogate it, as in (13c), this only affects the main clause but it does not affect the content of the dependent clause, which suggests that the dependent clause is presupposed. The speaker in (13) can assert, deny or question whether Liz was injured (the event described in the main clause), but he 
or she cannot assert, deny or question whether Liz's car did crash (the event described in the dependent clause). The presupposed status of the when-clause is further also reflected by the fact that it cannot be conjoined with a denial of its content without leading to a contradiction for the speaker, as in (13d), and by the fact that it is not easily open to debate, as illustrated in the strangeness of the dialogue in (13e).

(13) a. Liz was badly injured when her car crashed.

b. Liz was not injured when her car crashed.

c. Whatever happened to Liz? Did she get those injuries when her car crashed?

d. ?Liz was badly injured when her car crashed, but in fact her car did not crash.

e. A: Liz was badly injured when her car crashed.

B: Did her car really crash?

A: ?Well, I don't know.

The supposed general correlation between subordination and presupposition has repeatedly been called into question for complement constructions (see, for instance, Karttunen 1973; Kempson 1975: 66-70; and more generally Levinson 1983: 191-198 on problems with so-called "factive" complements), and if we look at adverbial constructions this idea does not in fact fare any better. Within the domain traditionally described as adverbial subordination, there are a number of constructions for which an association with presupposition is problematic, and as I will argue in this section, it is not a coincidence that this includes two of the constructions we are looking at here, viz. clauses of reason and purpose. If we look at the construction of reason cited in (9) above, for instance, repeated as (14a) below, applying the criteria for presupposition is not as clear-cut as with the when-construction in (13). Specifically, interrogating the main clause can in fact affect the content of the because-clause, which strongly suggests that it is not presupposed. Unlike the interrogative in (13c), the interrogative structure in (14b) can be interpreted as presupposing that Julia killed her husband for some particular reason, and asking whether he was cheating on her. While (13c) cannot be used in a context that tries to establish whether Liz's car crashed or not, the interrogative in (14b) can be used in such a context, for instance in searching for possible motives for the murder. Moreover, one can conjoin the construction of reason with a negation of the content of the because-clause, as in (14c), and still not contradict oneself, which again suggests that the becauseclause is not presupposed. Finally, the content of the because-clause is open to debate in a way that is not normally available to presupposed 
clauses, as illustrated in (14d), which shows that one can deny knowledge of it in response to challenges. Further evidence about the nonpresupposed status of reason clauses is provided in Section 3.1, where it is shown that they can also contain various types of modal marking, which is incompatible with presupposed status.

(14) a. Julia killed her husband because he cheated on her.

b. Whatever possessed her? Did she kill him because he cheated on her?

c. Julia killed her husband because he cheated on her, but she was wrong, he never cheated on her.

d. A: Whatever possessed Julia?

B: She killed him because he cheated on her.

A: Did he really?

B: Well, I don't know, but that's certainly what she thought.

Similar problems are found when dealing with constructions of purpose: again, determining presupposition is not straightforward in these contexts, as shown in (15) below. Does the structure in (15a) presuppose that the workmen got in? Not necessarily. Again, it is possible to conjoin the construction of purpose with a denial of the content of the so thatclause, without any contradiction, as shown in (15b). And as with reason constructions, the content of the so that-clause is open to debate and the speaker can deny knowledge of it, as shown in (15c).

(15) a. Larry opened the door so that the workmen could get in.

b. Larry opened the door so that the workmen could get in, but in fact they never got in.

c. A: Larry left the door open so that the workmen could get in. B: So did they get in?

A: I have no idea, but that was certainly his intention.

The reason why these particular construction types behave anomalously with respect to presupposition, I argue, is the existence of the mental state relation with the agent of the main clause that was described in the previous section. Presupposition, together with its complement of assertion, is something that essentially belongs to the domain of the speaker of a particular utterance: it is the speaker who asserts, questions, denies, or presupposes the truth of a proposition. If a particular subordinate clause is construed as the mental state of the agent of the main clause, however, this clause is relegated to a third party and therefore falls outside the domain of the speaker. In a construction of reason like (14), a becauseclause cannot be asserted or presupposed by the speaker if it belongs to the perspective of the agent of the main clause: it is Julia who thinks that 
her husband cheated on her, which leads her to the action described in the main clause. Similarly, in a construction of purpose like (15), the so thatclause is outside the domain of the speaker because it represents a mental state of the agent of the main clause: it is Larry who wants the workmen to be able to get into the house. To further support this argument about the incompatibility of presupposition and mental state relations, it can also be noted that the various types of evidence against presupposition, as described in (14c)-(14d) and (15b)-(15c) explicitly refer to the attitude of the main clause's agent. The strategy that is used to deny knowledge of the content of the because-clause or so that-clause in (14d) and (15c) is precisely to state that it is the agent's intention or the agent's personal motivation, and therefore not within the speaker's own domain. ${ }^{3}$

From this perspective, it is not a coincidence at all that constructions involving mental state relations run into difficulties with presupposition: because the subordinate clauses belong to the domain of a third party, their content is simply not within the control of the speaker to presuppose or assert. This can be compared to the domain of represented speech and thought, which also represents propositions as belonging to the perspective of some third party. With constructions of indirect speech, for instance, like the structures in (16) below, presupposition is equally irrelevant, for the same reason as the constructions studied here. The dependent clause in (16a) is construed as belonging to the perspective of the agent of the main clause, and is therefore not within the domain of the speaker to assert or presuppose. The same mechanisms of denial and challengeability apply here, as shown in (16b) and (16c).

(16) a. Sue said that she would come.

b. Sue said that she would come, but she did not come in the end.

c. A: Sue said that she would come.

B: And did she come?

A: No idea, but she said she would.

This is not to say, of course, that speakers cannot express any attitudes at all with respect to the content of such subordinate clauses. Most languages have evidential categories at their disposal that allow speakers to associate themselves with, or dissociate themselves from, propositions they report from other parties. Thus, the speaker who uses a construction of reason can insert an adverb like allegedly to mark his or her dissociation from the agent's perspective. The crucial point, however, is that such speaker attitudes do not apply directly to the event described, but only to the beliefs ascribed to the agent of the main clause. 


\subsection{Conclusion}

The arguments put forward in this section have shown that there is good semantic evidence to posit mental state relations as an essential semantic feature of constructions of purpose, reason and intended endpoint. In all three cases, the dependent clause does not just provide an adverbial-type elaboration of the event described in the main clause, but crucially also represents the content of a mental state that can be ascribed to the agent of that main clause, either as an intention or as a personal motivation. If we did not include such a feature in the semantic description of these constructions, it would be impossible to distinguish them from their close relatives of result, cause and endpoint, which at least in the English examples we have looked at are encoded by very similar formal means. Moreover, without the recognition of mental state relations it would also be very hard to explain the problems encountered with presupposition.

Semantic evidence for the relevance of mental states is not enough, however. The analysis presented in this section crucially leaves a number of questions unanswered that relate to the formal encoding of mental states. One such question is how mental state relations are actually encoded in the absence of any specific mental state predicate. In complement constructions of the believe-type illustrated in (1), there is a predicate in the main clause to explicitly mark the dependent clause as representing a mental state of the main clause's agent, but how does it work in adverbial-type constructions like the ones looked at here, especially if there are no mental state predicates in the main clause? A related question is how the pairs of English construction types investigated in Section 2.1 are to be distinguished formally if they are distinct semantically: for relations of cause and reason, for instance, there are no obvious formal features to distinguish the two types. In the following section, I will investigate the formal properties of purpose, reason and intended endpoint constructions in more detail, using data from broader range of languages, and I will show that there are a number of formal strategies that clearly reflect the presence of mental state relations in these constructions, some of which partly overlap with the domain of complement clauses.

\section{Formal reflections of mental states: crosslinguistic evidence}

In this section, I will complement the semantic evidence presented in the previous section by surveying the formal properties of constructions of purpose, reason and intended endpoint in a broader range of languages, 
Table 1. Languages used in this study

\begin{tabular}{|c|c|c|}
\hline Language & Genetic affiliation & Geographic location \\
\hline Abkhaz & North West Caucasian & Abkhaz Republic \\
\hline $\begin{array}{l}\text { Arabana- } \\
\text { Wangkangurru }\end{array}$ & Pama-Nyungan & Australia (South Australia) \\
\hline Arrernte & Pama-Nyungan & Australia (Northern Territory) \\
\hline Bininj Gun-Wok & Gunwinjguan & Australia (Northern Territory) \\
\hline Cubeo & Tucanoan & Colombia \\
\hline Emerillon & Tupi-Guarani & French Guyana \\
\hline Georgian & Kartvelian & Georgia \\
\hline Golin & Trans-New Guinea (Chimbu) & Papua New Guinea (Chimbu) \\
\hline Hatam & West Papuan & Indonesia (Papua) \\
\hline Hausa & Afro-Asiatic (Chadic) & Nigeria, Niger \\
\hline Huallaga Quechua & Quechuan & Peru \\
\hline Hua & $\begin{array}{l}\text { Trans-New Guinea } \\
\text { (Eastern Highlands) }\end{array}$ & $\begin{array}{l}\text { Papua New Guinea } \\
\text { (Eastern Highlands) }\end{array}$ \\
\hline Kana & Niger-Congo (Benue-Congo) & Nigeria \\
\hline Kannada & Dravidian & India \\
\hline Koyra Chiini & Nilo-Saharan & Mali \\
\hline Lele & Afro-Asiatic (Chadic) & Chad \\
\hline Lezgian & Nakh-Daghestanian & Russia (Dagestan) \\
\hline Maale & Afro-Asiatic (Omotic) & Ethiopia \\
\hline Marathi & Indo-European (Indo-Aryan) & India \\
\hline Meithei & Sino-Tibetan & India \\
\hline Mwotlap & Austronesian (Oceanic) & Vanuatu \\
\hline Noon & Niger-Congo (Atlantic) & Senegal \\
\hline Punjabi & Indo-European (Indo-Aryan) & India, Pakistan \\
\hline Slave & Athapaskan & Canada \\
\hline Usan & $\begin{array}{l}\text { Trans-New Guinea } \\
\text { (Adelbert Range) }\end{array}$ & Papua New Guinea (Madang) \\
\hline Wambaya & Mirndi & Australia (Northern Territory) \\
\hline Wari' & Chapakura & Brazil \\
\hline Yimas & Sepik-Ramu & Papua New Guinea (East Sepik) \\
\hline
\end{tabular}

listed in Table 1. The sample used is a convenience sample of twentyeight languages, but with twenty-one different genetic groups and a broad geographic range it provides a good indication of crosslinguistic tendencies in the formal makeup of purpose, reason and intended endpoint constructions.

On the basis of this sample, I will argue that there are at least three recurrent formal features in these constructions that explicitly reflect the presence of mental state relations, one relating to the internal structure of the dependent clause, another relating to the type of conjunction that is used to link the two clauses, and a third relating to higher-order constructional similarities with complement constructions. In Section 3.1, I 
will show that there is a tendency for clauses of purpose, reason or intended endpoint to be marked with some kind of mood category, which reflects their status as representing the mental state of some evaluating authority. In Section 3.2, I will show that the conjunctions used in these constructions often have formal affinities with conjunctions used in the domains of represented speech and thought, which can be regarded as a way to establish binding of mood categories in the dependent clause to the agent of the main clause. In the concluding section, I will show that in some cases there is also higher-level overlap with complement constructions as a whole, reflecting a tendency for unitary encoding of mental state relations.

\subsection{Mood categories in the dependent clause}

In general, mood markers can be defined as any type of linguistic element that marks an evaluation of the plausibility of a particular proposition (epistemic), or the desirability of a particular course of action (deontic, see Palmer [2001] and Verstraete [2001] for further details on the definition of mood used here). If we look at the way purpose, reason and intended temporal endpoint are encoded across languages, one striking feature of the constructions used is that the clause denoting the purpose, reason or intended temporal endpoint often contains such a mood marker.

In our survey, we can find mood markers in the dependent clause of at least one of the three constructions ${ }^{4}$ in the following languages: Abkhaz (purpose; Hewitt 1987: 38-40), Arabana-Wangkangurru (intended endpoint, purpose; Hercus 1994: 184-186, 190, 269-270), Arrernte (intended endpoint, purpose; Wilkins 1989: 196-197, 236-238), Bininj Gun-Wok (reason; Evans 2003: 650-651), Emerillon (purpose; Rose 2003: 489), Georgian (purpose; Hewitt 1987: 23-25), Golin (purpose; Loughnane 2003), Hausa (purpose; Jaggar 2001: 640), Huallaga Quechua (purpose; Weber 1974; 292), Hua (purpose; Haiman 1980: 443), Kana (purpose; Ikoro 1996: 280), Kannada (purpose; Sridhar 1990: Section 1.1.2.4.2.3), Koyra Chiini (intended endpoint; Heath 1999: 297), Lezgian (purpose; Haspelmath 1993: 393-394), Maale (purpose; Amha 2001: 186), Marathi (purpose; Pandharipande 1997: Section 1.1.2.4.2.3), Mwotlap (purpose; François 2001: 859-860), Noon (intended endpoint; Soukka 2000: 225, 279-280), Slave (purpose; Rice 1989: 1259-1261), Wambaya (purpose; Nordlinger 1998: 208-209), Wari' (reason; Everett and Kern 1997: 98-99), Yimas (purpose; Foley 1991: 402-403). 
It is obviously impossible to discuss and exemplify each of these cases in detail, but I will discuss one instance for each construction, looking both at the construction as such and at the semantics of the mood marker as reflected in its use in main clause contexts. In the Athapaskan language Slave (Rice 1989: 1259-1261), purpose constructions are marked by the complementizer gha and the use of optative mood on the verb of the purpose clause, as illustrated in (18) below, where the verb 'eat' in the clause denoting the purpose is marked as optative. The fact that the optative is indeed a mood element can be illustrated with its use in main clauses, where it normally "expresses desire or potential" (Rice 1989: 548), as in (19).

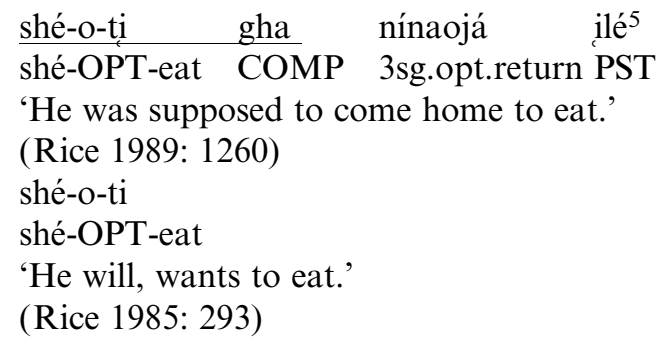

In the Gunwinjguan language Bininj Gun-Wok (Evans 2003: 650-651), reason constructions can contain the apprehensive particle wardi, as in the structure in (20) below, where the clause denoting a reason (itself complex, with a conditional protasis and apodosis) is introduced by wardi. Again, the fact that this particular element is a mood marker can be deduced from its use in main clause contexts, where it is "normally employed in clauses with the meaning 'this unpleasant/dangerous thing might happen" (Evans 2003: 650). This is the case in (21) below, where it marks the speaker's assessment of the undesirability of a future event.

\begin{tabular}{lllll} 
marrek & \multicolumn{2}{c}{ ngalyod } & \multicolumn{3}{c}{ birri-kurm-eninj ya ku-wardde } \\
NEG & \multicolumn{2}{c}{ rainbow.serpent } & 3aP-put-IRR & yeah LOC-rock \\
marrek wardi & birri-bimbu-yi & wanjh & ben-ngu-yi \\
\cline { 2 - 5 } not & might & 3a/3P-paint-IRR & then & 3/3PIP-eat-IRR
\end{tabular}
'They didn't put rainbow serpents when they painted on the rock, because if they painted them then the snake might have consumed them.'

(Evans 2003: 651)

$$
\begin{array}{lll}
\text { na-marrgon } & \text { wardi } & \text { an-do-ng } \\
\text { I-lightning } & \text { might } & 3 / 1 \text {-strike-NP }
\end{array}
$$

'Lightning might strike me.'

(Evans 2003: 367) 
Finally, in the Pama-Nyungan language Arrernte (Wilkins 1989: 196), clauses that encode intended temporal endpoints contain verbs marked with purposive mood, like the construction in (22) below, where the verb denoting the intended endpoint of the child's crying (the mother's return) is marked as purposive. In spite of the label used for this category, purposive markers can be regarded as moods in Arrernte, because one of their typical uses in main clauses is modal: purposive-marked verbs "may occur as the main verb in an utterance (with no auxiliary) to convey the sense that the S/A 'must' or 'should' do the verb action" (Wilkins 1989: 236), as in (23) below, where it marks the speaker's judgment that going back would be a desirable course of action.

(22) $\mathrm{Re}$ artne-pe-kwete-artne-ke m-ikwe

3sgS cry-FREQ-still-rdp-pc mother-3KINPOSS

petyalpe-tyeke-kerte.

come back-PURP-PROP

'He kept on crying until his mother returned.'

(Wilkins 1989: 196)

Re kwenhe lhe-tyeke, m-ikwe rlkerte

3 sgS ASSERT go-PURP, mother-3KinPOSS(S) sick big-ABL

'He should go because his mother is seriously ill.'

(Wilkins 1989: 236)

From the perspective of the present study, the use of mood markers in these constructions is relevant to the problem of mental states. Given that mood generally serves to mark an evaluation of the plausibility or desirability of a particular event (as reflected by the main clause uses in [19], [21], and [23]), presence of a mood marker in a particular construction reflects the perspective of some authority who makes this judgment. More specifically, the use of a mood marker in the clauses denoting purpose, reason or intended temporal endpoint in (18), (20) and (22) signals the presence of some evaluating authority whose mental state is represented in that clause: the use of optative in the Slave purpose clause in (18) signals that this clause represents the perspective of someone who regards eating as desirable, the use of apprehensive in the Bininj Gun-Wok reason clause in (20) signals that this clause represents the mental state of someone who regards an attack from the snake as undesirable, and the use of purposive in the Arrernte intended endpoint clause in (22) signals the perspective of someone who finds the return of the mother desirable. Thus, the mood markers used in clauses of purpose, reason and intended temporal endpoint can be regarded as clear formal reflections of the fact that these clauses represent someone's mental state. 
This actually fits in nicely with the overall distribution of mood marking in subordinate clauses. As shown by Givón (1994), for instance, mood is typically found in subordinate clauses that have modal overtones. This includes not only the types studied here, but also types like conditional or counterfactual constructions, in which mood serves to signal the speaker's evaluation of the event described as hypothetical or counterfactual (see further in Verstraete forthcoming). Interestingly, these other types are also problematic in terms of the classic presupposition analysis of subordinate clauses, because they serve to mark supposition by the speaker rather than presupposition. What distinguishes the constructions studied here from other mood-marked subordinate clauses, however, is that it is not the speaker who evaluates (see also Lakoff [1968] for a similar argument in the domain of complement constructions). In the default interpretation of modal categories, the judging authority is the speaker, as in all of the main clause contexts illustrated in (19), (21), and (23): it is the speaker who judges eating to be potential or desirable in (19), who thinks of lightning as undesirable in (21), and who thinks of going back as desirable in (23). In constructions of purpose, reason and intended endpoint, however, such an interpretation is impossible. It is not possible to interpret the mood marker as representing a judgment by the speaker while at the same time maintaining an interpretation of these constructions in terms of relations of purpose, reason or intended temporal endpoint. In the Bininj Gun-Wok construction illustrated in (20) above, for instance, taking the apprehensive particle wardi as representing a judgment of undesirability by the speaker would destroy the interpretation of reason: "they did not draw rainbow serpents, I am afraid that the snake would attack them" is definitely not a statement of reason. In the reason interpretation, it is crucially not the speaker who is afraid of the snake attack, but rather the agents of the main clause, for whom fear of attack is their motivation not to draw serpents. ${ }^{6}$ Similarly, the optative mood in the Slave construction in (18) cannot be interpreted as marking the desire of the speaker without losing the purposive interpretation of the entire structure. This would result in a reading like 'He was supposed to come home, he will/wants to eat', which is obviously not an interpretation of purpose. Again, the crucial feature is that the judgment marked by the modal category is that of the agent of the action described in the main clause. Finally, the purposive mood in the Arrernte construction in (22) cannot be linked to the speaker without losing the feature of intention: interpreting it as expressing the speaker's desire, as is common in main clause contexts like (23), would lead to a reading like 'The child kept on crying, I want his mother to return'. Crucially, however, it is not the speaker's desire that the mother return, but rather that of the child, i.e., the modal 
assessment marked by the purposive element is again not the speaker's but that of the agent of the main clause.

In fact, mood marking is also one way to formally disambiguate the pairs of English constructions studied in Section 2.1, which differ in terms of the semantic feature of a mental state relation but otherwise seem to be formally indistinguishable. Mood is definitely not the sole distinguishing factor from a crosslinguistic perspective, but at least for the English structures it can make the difference. If we take the pair of reason and cause, for instance, repeated as (24) and (25) below, the apparent formal identity is disrupted if we try to replace the indicative mood in the dependent clause by a modal verb (see also Hengeveld 1998: 346-347). Substitution by a modal verb is unproblematic in the reason construction in (24a), as reflected by the acceptability of might in (24b), whereas it seems to be excluded in the cause construction in (25a), as reflected by the unacceptability of might in (25b).

(24) a. Julia killed her husband because he cheated on her.

b. Julia killed her husband because he might have cheated on her.

(25) a. Julia was late because she was stuck in a traffic jam.

b. ?Julia was late because she might have been stuck in a traffic jam.

The reason for this difference is the same as with the other constructions investigated in this section. The construction of reason allows marking of mood because it introduces the perspective of the agent of the main clause, and any marker of mood will be linked back to this agent. Thus, in (24b), the modal element might is interpreted as Julia's might, it is her belief about the possibility of adultery that leads her to kill her husband. The construction of cause, on the other hand, does not allow marking of mood, not because it does not belong to anybody's perspective, but because the cause is presupposed to be true: any marking of possibility, plausibility or desirability would clash with this presupposition. Other presupposed types of adverbial clauses are just like the construction of cause in that they do not allow mood marking, as in the when-clause discussed in (13): compare * Liz was badly injured when she may/might have had an accident. In this perspective, the behavior of mood markers further supports the analysis of presupposition presented in Section 2.2 above. The diverging acceptability of mood markers nicely corresponds to the distinction between the traditional presupposed types of adverbial clauses and the non-presupposed types studied here.

In short, what is special about the use of the mood categories in the constructions investigated here is that the evaluation they express cannot 
be linked to the speaker, as is the default case in the context of main clauses (see [19], [21], and [23]). In order to obtain the readings of purpose, reason and intended temporal endpoint, the mood marker must instead be linked across the boundary of the clause, to the agent of the main clause. In this perspective, the use of mood markers in the dependent clause of purpose, reason and intended endpoint constructions can be seen as a clear formal reflection of the fact that they mark the mental state of the agent of the main clause. This is actually a feature which they share with complement constructions, in which mood elements equally tend to mark a particular judgment of desirability or plausibility from the perspective of the agent of the main clause (see, for instance, Lakoff 1968 and Givón 1994). To give one example from Arrernte, the purposive mood found in the intended endpoint construction in (22) above is equally found in complement constructions governed by verbs like 'force', as in (26) below, where it marks the judgment of desirability made by the agent of the verb in the main clause.

Kwementyaye-le re-nhe uterne-ke nterte ne-tyeke.
Kwementyaye-ERG 3sg-ACC force-pc quiet be-PURP
'Kwementyaye ordered (forced) him to be quiet.'
(Wilkins 1989: 237)

This comparison with the complement domain immediately raises a second question, however: if there is a mood element that marks some kind of modal judgment in the dependent clause, and if we need semantic binding of this element to the agent of the main clause, how is such binding encoded formally? In complement constructions, there is of course the predicate in the main clause, like the verb 'force' in (26), to explicitly mark the dependent clause as belonging to the perspective of the agent of the main clause. But how does this happen in adverbial constructions like the ones we look at here, which do not necessarily have any mental state predicates in their main clause? In the following section, I will explore one formal strategy that seems to be a crosslinguistically rather common way to link mood in the dependent clause to the agent of the main clause.

\subsection{Agent-binding conjunctions}

The second characteristic that can be regarded as a formal reflection of mental state relations does not relate to the internal structure of the dependent clause, like the mood categories from the previous section, but rather to the nature of the conjunctions that are used to link the two 
clauses in constructions of purpose, reason and intended temporal endpoint. If we look at the semantics of these conjunctions across the sample of languages investigated here, it is obvious that the three constructions do not just use conjunctions that are semantically specialized in purpose, reason or intended temporal endpoint (or shared with closely related adverbial relations like result or cause). While there are languages like English that do use relatively specialized conjunctions, there is also a strong crosslinguistic tendency for these constructions to use conjunctions from an entirely different functional domain, viz. that of reported speech. Constructions of purpose, and to a lesser extent also reason, often use conjunctions that are shared with constructions of reported speech, or that are at least diachronically related to verbs of speech.

To give an example of the latter strategy, one way to encode reason and purpose in the Nakh-Daghestanian language Lezgian is to use the conjunction luhuz/lahana, which derives from a verb of speech and has as its "original meaning 'saying/having said"” (Haspelmath 1993: 390). Thus, for instance, the clause of reason in (27) below, which represents the old woman's personal motivation for putting the lock on the door, is not related to the main clause by a conjunction that specifically denotes reason or some related semantic domain, but rather by luhuz. Similarly, the clause of purpose in (28) does not use a semantically specific conjunction to signal its status as purposive, but again uses a form that is related to a verb of speech, viz. lahana.

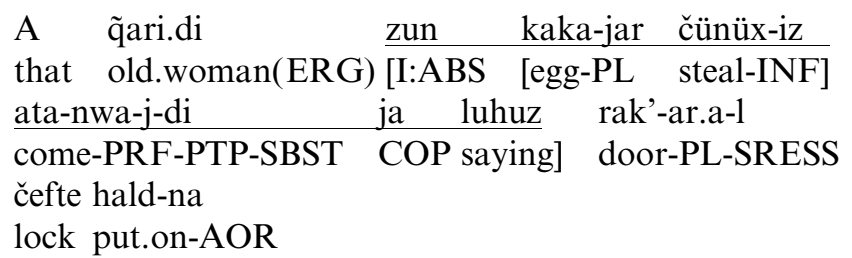

'That old woman put the lock on the door because [she thought that] I had come to steal the eggs.'

(Haspelmath 1993: 391)

(28)

\begin{tabular}{llll} 
k'wal.i-z & ččara & kas hax & t-awu-raj \\
\hline [house-DAT & strange person go.in(PER) & NEG-do-OPT \\
lahana ada & rak agal-na & \\
saying] he(ERG) & door close-AOR &
\end{tabular}

'He locked the door so that no stranger could come into the room.'

(Haspelmath 1993: 393)

Using conjunctions derived from verbs of speech is not the only formal feature that links purpose and reason with the domain of reported speech. 
Another strategy that is found quite often in the languages surveyed here is the use of a conjunction that is formally shared with the domain of reported speech. In the Dravidian language Kannada, for instance, the conjunction that is used to mark a relation of quotation is anta, as in (29) below, where it links a quoted clause to the verb of speech 'whisper' in the main clause. Use of this conjunction is not restricted to the domain of reported speech, however. It can equally be found in constructions of purpose and reason, the main formal difference being that in these constructions there need not be any verb of speech in the main clause. Thus, for instance, the purpose clause in (30) below is linked to the main clause by the same conjunction anta, as is the reason clause in (31).

$\begin{array}{llllll}\text { rame:Sa jyo:tiya } & \text { kiviyalli } & \text { "ni:ne: } & \text { nanna } & \text { ra:Ni" } \\ \text { Ramesha Jyoti.POSS } & \text { ear.LOC } & \text { you.EMPH } & \text { my } & \text { queen } \\ \text { anta pisuguTTida } & & & & \\ \text { QUOT } & \text { whisper-PST-3sm } & & & \end{array}$

'Ramesha whispered in Jyoti's ear, "You are indeed my queen.", (Sridhar 1990: 1)

(30) emTia:rnalli u:tappa tinno:Na anta mane biTTu MTR.LOC utappa eat.SUG QUOT house leave-PP horaTa leave.PST. $3 \mathrm{sm}$ 'He left home to eat utappa at the MTR.' (Sridhar 1990: 73)

ni:nu obbane: $\quad$ bande
you one-person(m).EMPH come.PST.2s QUOT my
magaLige asama:dha:na
daughter.DAT dissatisfaction
'My daughter is unhappy that/because you came alone.'
(Sridhar 1990: 76)

The relation between conjunctions of reported speech and constructions of purpose and reason has often been noted in the literature, and has sometimes been described as an areal feature, specifically for South Asia (Bashir 1988; Saxena 1995) and the Bantu area (Güldemann 2002). The languages surveyed here, however, show that this feature is not restricted to these areas and is actually more widespread. Apart from South Asian languages like Kannada, Meithei, Marathi and Punjabi in the set of languages described here (Sridhar 1990: 72-74, 74-76; Chelliah 1997: 186187; Pandharipande 1997: Section 1.1.2.4.2.3, Section 1.1.2.4.2.4; Bhatia 1993: 74-75), it is also found in languages of South America (Cubeo in Morse and Maxwell 1999: 174-177; Emerillon in Rose 2003: 490-492; Wari' in Everett and Kern 1997: 97-98), Papuan languages (Golin in 
Loughnane 2003; Hatam in Reesink 1999: 128-129; Usan in Reesink 1987: 255; Yimas in Foley 1991: 402-403), languages of the Caucasus (Abkhaz in Hewitt 1987: 38-40; Georgian in Hewitt 1987: 27-28), and Chadic languages (Lele in Frajzyngier 2001: 405-409, and more generally Frajzyngier 1991, 1996 on de dicto complementizers in Chadic and beyond).

This wide distribution shows that the relation with the domain of reported speech is not restricted to a particular area, and suggests that this feature may have some functional motivation. In terms of the analysis developed in this study, the use of conjunctions shared with reported speech can be regarded as a formal reflection of the fact that the content of the adverbial clauses studied here does not belong to the perspective of the speaker, but rather to that of the agent of the main clause. In contexts of reported speech, the function of conjunctions like anta in (29) is to link the dependent clause to the perspective of the agent of the main clause rather than to the speaker, i.e., to signal that it is not the speaker but Ramesha who calls Jyoti his queen. The fact that such conjunctions equally appear in constructions of purpose and reason can be related to the mental state relation that was identified in the previous sections, and can be regarded as a formal means to establish binding to the agent of the main clause: it is the agent of the main clause rather than the speaker who wants to prevent strangers from coming in (28), and it is the agent of the main clause rather than the speaker who intends to eat in (30). For the Lezgian constructions, Haspelmath argues explicitly that the dependent clause represents a "highly subjective motivation" (Haspelmath 1993: 390,393 ) of a participant in the main clause, thus distinguishing the constructions from closely related counterparts like cause and result, in exactly the same way as was argued for the parallel English constructions in Section 2.1, except that in the Lezgian constructions there is explicit formal marking to signal binding to the agent of the main clause.

As with the phenomenon of mood marking discussed in the previous section, the use of conjunctions that originate in the domain of represented speech is again a feature that is shared with complement constructions. As argued in Saxena (1995), the extension of conjunctions of represented speech to constructions of reason and purpose can be regarded as part of an implicational hierarchy, in that any language that uses these conjunctions in contexts of reason and purpose will also use them for various types of complement constructions (see also in Stirling [1993: 259263] for a similar hierarchy in the related domain of logophoricity, with a more detailed analysis of implicational relations between various types of complements). The widespread use of these conjunctions beyond the domain of represented speech is also the main reason why the 
constructions discussed here are not analyzed as basically constructions of represented speech that have some pragmatic association with purpose and reason (see, for instance, Hengeveld 1998: 336-337), but as genuinely distinct constructions using conjunctions for agent binding that are derived from, or otherwise associated with, constructions of represented speech.

The formal marking of agent binding with conjunctions shared with represented speech further ties in nicely with two other properties of these constructions that were discussed in the previous sections, namely, the tendency to use mood marking in the dependent clause and the problems with presupposition. One question that was raised at the end of the section dealing with mood was how the mood categories in the dependent clause can be linked to the agent of the main clause in the absence of any 'perspectivizing' predicate in that main clause, either a mental state predicate or a speech predicate. The type of structure investigated here illustrates a formal strategy to get around this problem. The purposive structures in (28) and (30) above both use mood markers in their dependent clause (optative mood in [28] and suggestive mood in [30]). In these constructions, linking to the agent of the main clause is established not by a perspectivizing predicate in the main clause, but by a conjunction that is typically associated with such predicates, like anta in (30), or one that is diachronically derived from such a predicate, like lahana in (28). In other words, these constructions shift the burden of establishing the mental state relation from the predicate of the main clause, as is typical in complement constructions, to the conjunction that is used to link the two clauses.

In addition to its interaction with mood, the formal marking of agent binding discussed here can also throw some more light on the problem of presupposition dealt with in Section 2.2. It was shown there that the three construction types are not presupposed like many other types of adverbial clauses, and it was argued on semantic grounds that this was because the dependent clause belongs to the perspective of the agent of the main clause and is therefore outside the control of the speaker to presuppose or assert. The crosslinguistic patterns exemplified here provide formal corroboration of this semantic argument. Semantically, the reason clause in (27) cannot be regarded as presupposed by the speaker in any way, just like the English reason clause in (14): it is only the old woman who believes that the speaker has come to steal the eggs, but definitely not the speaker himself (see Haspelmath 1993: 290). Unlike with the English construction, however, this perspectivization is overtly reflected in the use of the "saying"-conjunction luhuz, which can be regarded as a formal marker of the link to the agent of the main clause. 


\subsection{Conclusion: adverbial clauses or complement clauses?}

The crosslinguistic analysis of purpose, reason and intended temporal endpoint in this section has provided further evidence to support the arguments about the semantic relevance of mental state relations adduced in the previous section, and at the same time it has identified two interlocking formal characteristics that could be regarded as a specific constructional 'template' for these semantic domains across languages. One aspect of this template specifies that the internal structure of the dependent clause will typically contain some kind of mood element, to mark the clause as expressing an evaluation of plausibility or desirability, and another aspect specifies that if there is a conjunction-like element linking the two clauses, this will typically establish a link to the agent of the main clause, for instance by virtue of an association with constructions of reported speech.

On the basis of this template, we can now also go back to the question posed at the outset of this article: where do the constructions of reason, purpose and intended endpoint belong in the typology of complex sentence types? Traditionally, they have been included in the adverbial category on the basis of their function relative to the main clause: they do not describe the content or object of some predicate in the main clause as in complement constructions, but instead they provide adverbial modification of the main clause. While this classification is definitely a relevant feature in the description, the analysis in this study has shown that the relation between main clause and dependent clause in these constructions cannot just be described in terms of adverbial modification. A semantically and formally adequate analysis must also recognize the existence of a mental state relation between the dependent clause and the main clause, i.e., the fact that the dependent clause in these constructions is construed as a mental state of the agent of the main clause. This feature has not traditionally been associated with adverbial clauses and the analysis in Section 2, which contrasted purpose, reason and intended endpoint with a number of closely related constructions suggests that most other adverbial clauses do not in fact have such a mental state relation. Instead, the feature of mental state relations can be regarded as more typical of the domain of complement constructions: many, if not all, complement constructions have some feature of what Halliday (1985: 196-198; Halliday and Matthiessen 2004: 377-379) has called "projection", the construal of the dependent clause as being projected through the consciousness of some participant that is not the speaker. In many cases, this relation will be made explicit by the use of predicates in the main clause that explicitly denote such acts of projection, either mental state predicates or predicates of speech. 
Table 2. The intermediate position of purpose, reason and intended endpoint

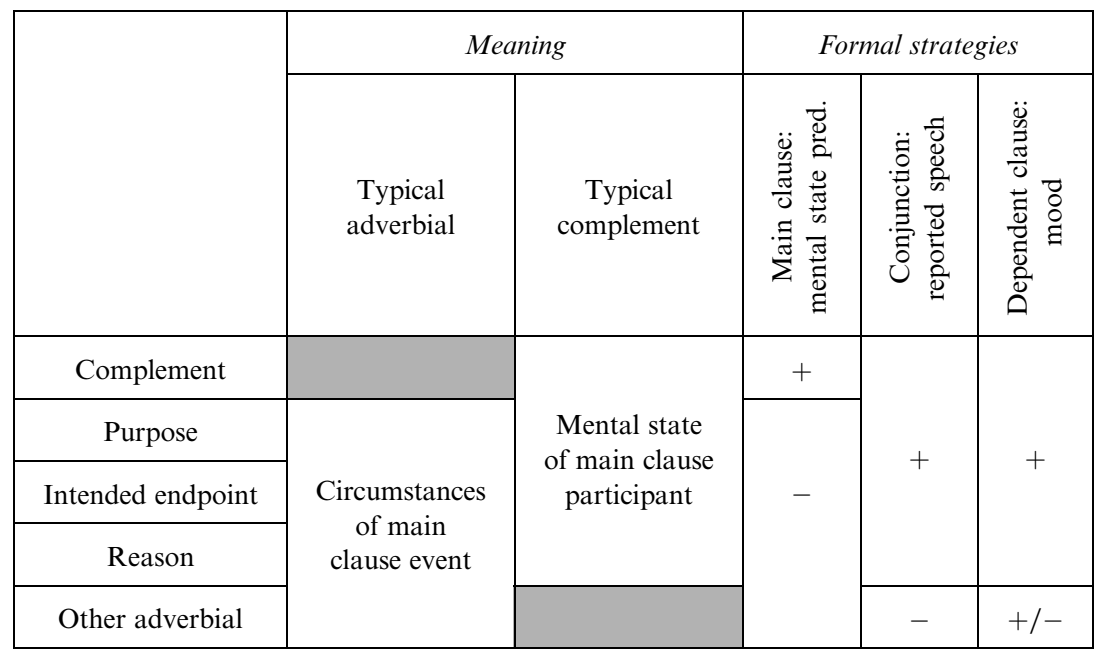

In this perspective, the constructions of purpose, reason and intended endpoint can be regarded as intermediate between the domains of complementation and adverbial modification, because they have to be defined on the basis of features from both domains. Like other adverbial constructions, they specify circumstances framing the event described in the main clause, as reflected by the fact that their main clause need not contain any predicate of speech or of mental states. Like complement constructions, however, their dependent clause is construed as a mental state of the agent of the main clause, formally reflected by the presence of a mood element in the dependent clause, and by the use of conjunctions that specifically relate this mood element back to the agent of the main clause. Table 2 summarizes the formally and semantically intermediate status of these constructions as they have been described so far.

If we look at the crosslinguistic data surveyed here, the closeness of these three constructions to the domain of complementation is also reflected by higher-level formal overlap with complement constructions. So far, the discussion has been confined to constructions with finite dependent clauses, but if we also take nonfinite constructions into account, the similarity with the domain of complementation becomes even more striking, especially for relations of purpose. In many of the languages surveyed, nonfinite clauses of purpose are formally completely identical to nonfinite complements of manipulative and desiderative main verbs. In English, for instance, both constructions of purpose like (32) below and complements of verbs like tell/force/urge in (33) take an infinitival dependent clause, 
the main formal difference between the two constructions being the type of predicate used in the main clause.

(32) I saved money to go away.

(33) I told/forced/urged him to go away.

The same construction-level overlap with complementation can in fact be found with finite constructions of purpose in some other languages, as in the Omotic language Maale, where the conjunction gudi in combination with a verb marked for the future imperfective can be used both as a complement to a manipulative or desiderative verb, as in (34) below, or as a purpose clause, as in (35). As noted explicitly by Amha (2001: 178), the only formal difference that decides about adverbial or complement status is in the type of predicate used in the main clause and its relation to the subordinate clause.

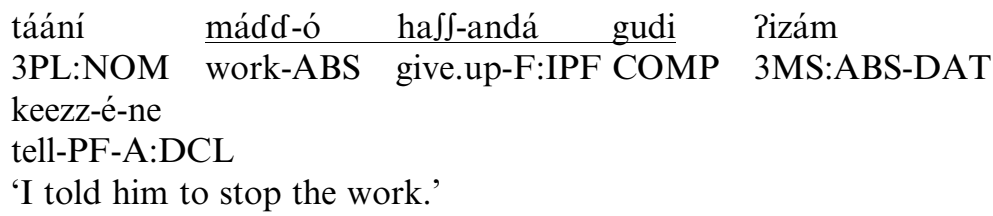

(Amha 2001: 179)

$\begin{array}{lllll}\text { Ríní } & \text { na??-á } & \text { Pam?-ó } & \text { Janc-andá } & \text { gudi } \\ \text { 3MS:NOM } & \text { child-NOM } & \text { coffee-ABS } & \text { sell-F:IPF } & \text { COMP } \\ \text { bookk-ó } & \text { dákk-é-ne } & & & \\ \text { market-ABS } & \text { send-PF-A:DCL } & & \end{array}$

'He sent the girl to the market to sell coffee.'

(Amha 2001: 187)

\section{Theoretical implications: layering}

From a theoretical perspective, the semantic arguments from Section 2 and the structural features from Section 3 raise a number of questions for the way they should be represented in a theoretical model. In this concluding section, I will argue that the set of constructions studied here provides important evidence for structural layering, more specifically the distinction between interaction-related and description-related layers of organization as proposed in various functional models of grammar, as well as finer subdivisions within the interaction-related layer.

It is a basic characteristic of many functional models of language, such as Functional Grammar (Hengeveld 1989; Dik 1997), Systemic Functional Grammar (Halliday 1985; Halliday and Matthiessen 2004), and Role and Reference grammar (Foley and Van Valin 1984; Van Valin 
and LaPolla 1997), that clausal structures are modeled in terms of a number of nested layers associated with different hierarchically ordered functional domains of the clause, such as the predicate, the state of affairs and the illocution. Although the nature and definition of the structural layers assumed in these models varies quite a bit (see Butler 2003), there is one basic structural split that most ${ }^{7}$ seem to agree on, viz. the distinction between an interaction-related layer of organization, basically those aspects of clause structure that encode speaker attitude and speaker-interlocutor interaction, and a description-related layer of organization, basically those aspects of clause structure that encode the construal of the event described in the clause.

The evidence used to support such a fundamental split between two layers of organization comes from various sources, but it can be summarized in terms of three basic types of arguments for layered structure, one of which is particularly relevant to the construction types investigated in this study. The first argument concerns functional and structural differentiation. Within the set of elements and structures that make up a clause, one can make a functional distinction between those aspects that serve to encode interaction, like modal elements, evidential markers or illocution markers, and those aspects that serve to encode event description, like argument structure or predicate types. Crucially, this functional distinction can also be shown to correlate with divergent formal behavior, in the sense that interaction-related material is in a different structural relation to the rest of the clause. As argued by McGregor (1997), elements like modal or evidential markers or illocution particles cannot be described in terms of the constituency relations that characterize the rest of the clause, but they are in a relation of scope to the remainder of the clause. Verstraete (2003) provides further evidence for this structural difference, showing how the interaction of these elements with focus structure goes against any type of constituency analysis. The second type of argument that is used in support of layered structure is the way adjuncts can single out either interaction-related or description-related aspects of clause structure as their target. To take a classic example from Ross (1970), an element like frankly in English can take at least two targets in the structure of the clause it is associated with: it can relate to the description of the event, as in George answered the judge's questions frankly, and it can relate to the interaction between speaker and interlocutor, as in Frankly, did George tell the truth in court? To accommodate such variable attachment of adjuncts, a model of the clause must at least be able to distinguish between interaction-related and description-related aspects of structure. Further evidence along these lines is presented in Hengeveld (1989), Dik et al. (1990), and Verstraete (1998). 
The third type of argument in support of layering, and to my mind the most decisive one in a structural sense, relates to the variable status of the interaction-related layer in different types of complex sentences, first elaborated in detail by Dik and Hengeveld (1991) and Hengeveld (1996, 1998). While main clauses by definition have an interaction-related layer of organization - otherwise they would not be able to function as speech acts in discourse - this is crucially not the case for dependent clauses in various types of complex sentences, in which the dependent clauses can be classified according to the absence of different aspects of interactionrelated organization. As shown in Verstraete (2004, 2005), for instance, the domain of adverbial subordination in English can be defined as a whole in terms of the structural diagnostic of the absence of an illocutionrelated layer of organization. In the coordinate but-construction in (36) below, for instance, the dependent clause allows various permutations of illocutionary marking, as shown by the contrast between declarative and interrogative in (36a) and (36b)-(36c). By contrast, in the subordinate after-construction in (37), this type of variation in illocutionary marking is not possible, as reflected in the unacceptability of the interrogative structure in (37b).

(36) a. He is a good singer, but he doesn't function well in the band.

b. He is a good singer, but why has he never been able to get along with the rest of the band?

c. He is a good singer, but has he ever been able to get along with the rest of the band?

(37) a. The band split after the singer left.

b. *The band split after why did the singer leave?

c. *The band split after did the singer leave?

The restriction to declarative in the after-clause in (37) points towards neutralization of the paradigm of illocution markers, and therefore also to absence of the illocutionary function (see Verstraete [2004] for more detailed arguments in this respect). In functional terms, this restriction corresponds to the common-sense understanding of subordinate structures as not encoding any speech act on their own, but instead depending on a main clause that does encode a separate speech act (on this general functional definition of subordination, see, for instance, Bossong 1979; Foley and Van Valin 1984; Hengeveld 1998; Cristofaro 2003). In the context of arguments about layering, what the distinction between coordinate structures like (36) and subordinate ones like (37) shows is that the illocutionrelated layer of organization is in fact variable, and can be stripped away in non-main clause contexts. Any model of clause grammar that is to account for these constructions and the differences between them should be 
able to accommodate this type of variability, and the best way to do so is to adopt a layered approach to clause structure, i.e., to recognize that illocution-related aspects of structure constitute a structurally separate layer of organization that can be stripped away in various contexts.

In this perspective, the argument presented in this article about the presence and absence of mental states in adverbial clauses can be interpreted along the same lines, and can be used as evidence for a refinement of our understanding of internal layering within the interaction-related part of clause structure. The main difference between purpose, reason and intended endpoint and other adverbial clauses, as argued throughout this article, is that in these constructions the dependent clause represents somebody's mental state. What this means in semantic terms is that the clause is not merely a description of some event, as in other adverbial clauses, but that it is also subject to an evaluation of its plausibility or desirability, formally reflected in the marking of mood. This type of distinction within the adverbial domain further confirms the structural importance of distinguishing between interaction- and description-related layers of organization, because it shows once again how aspects of interaction-related organization are structurally variable within complex sentences. Apart from the illocutionary organization whose variability was illustrated in (36) and (37) above, modal organization can equally be regarded as a variable rather than an inherent feature of clause structure. Purely adverbial clauses like the temporal clause in (38a) merely describe an event without allowing any modal judgment with respect to this event, as reflected in the unacceptability of modal verbs like may in (38b), while the construction types investigated here, like the purpose clause in (38c), do allow modal judgments, as marked by the modal of desirability may.

(38) a. Everybody leaves after the priest has given the blessing

b. *Everybody leaves after the priest may have given the blessing.

c. Everybody leaves so that the priest may talk with the couple in private.

In addition to strengthening the case for the structural distinctness of an interaction-related layer, however, the variability of modal organization also points towards the need to recognize finer subdivisions within this interaction-related layer. Although the purpose construction allows modal marking, as illustrated with may in (38c), it is like other subordinate constructions in that it does not allow illocutionary marking, as illustrated by the unacceptability of the interrogative in (39).

(39) *Everybody leaves so that may the priest talk with the couple in private? 
Table 3. Distinctions within the interaction-related layer

\begin{tabular}{lll}
\hline Modality & Illocution & Examples \\
\hline- & - & $(37),(38 \mathrm{a}),(38 \mathrm{~b})$ \\
+ & - & $(38 \mathrm{c}),(39)$ \\
+ & + & $(36)$ \\
\hline
\end{tabular}

This shows that within the interaction-related layer of clause structure, there are at least two aspects that can vary independently in different types of complex sentences. The contrast between (36) and (37) shows that there are complex sentences with and without illocutionary force in the dependent clause, but the contrast between (38c) and (39) also shows that for the type without illocutionary force, there is a further distinction between constructions with and without modal judgments in the dependent clause.

This distinction, schematically represented in Table 3 , corresponds closely to Hengeveld's (1998) distinction between layers of proposition and illocution within the interaction-related organization of the clause, and it is corroborated by evidence from the anchoring of adjunct categories (see Dik et al. 1990 and Verstraete 1998). What the analysis presented here can add to this is an explanation of why these two components can vary independently, and how it is possible to have modal judgments in a clause that does not have any illocutionary force. Semantically and pragmatically, this is a rather puzzling combination, for how can a clause encode a modal judgment if it does not even encode a speech act of its own? In terms of the analysis proposed here, the answer is straightforward. This combination of features is possible if the responsibility for the modal judgment is relegated from the speaker to a third party, in this case the agent of the main clause. As long as the modal judgment encoded in a structure without illocution does not belong to the speaker, there is no inherent contradiction.

Received 22 February 2006

Revised version received

Fund for Scientific Research-Flanders

4 April 2007

University of Leuven

\section{Notes}

1. An earlier version of this article was presented at the International Language and Cognition Conference in Coffs Harbour. I would like to thank the members of the audience, particularly Alice Gaby, for very helpful suggestions, and Chris Butler, Miriam Taverniers and two anonymous reviewers for very useful comments on previous drafts. The 
usual disclaimers apply. Correspondence address: Department of Linguistics, University of Leuven, Blijde-Inkomststraat 21, 3000 Leuven, Belgium. E-mail: jean-christophe. verstraete@arts.kuleuven.be.

2. It will be noted that the constructions in (4)-(6) can also have readings of result, cause and temporal endpoint. This ambiguity, and the semantic feature that distinguishes the two sets of readings, will be discussed in more detail in Section 2.1.

3. The problems with presupposition are clearest for constructions of purpose and reason, but reference to the beliefs of the agent of the main clause might also be the way to cancel presupposition for intended endpoint constructions. Compare A: He just kept reworking his thesis until it could be accepted by the examiners. B: And did they accept it? A: I have no idea, but that was certainly what he wanted.

4. Purpose clauses form a clear majority in the sample, though this can probably be attributed to the fact that they belong to the standard set of constructions examined in descriptive grammars, unlike constructions of intended endpoint and reason (as distinct from cause).

5. The following abbreviations are used in the glosses: ABL ablative, ABS absolutive, ACC accusative, AOR aorist, ASSERT assertion, A:DCL affirmative declarative, COMP complementizer, COP copula, DAT dative, EMPH emphatic, ERG ergative, F future, FREQ frequentative, INF infinitive, IPF imperfective, IRR irrealis, KINPOSS kin possessive, LOC locative, NEG negative, NOM nominative, OPT optative, PC past completive, PER periphrasis form, PF perfective, PL plural, POSS possessive, PRF perfect, PROP proprietive, PST past, PTP participle, PURP purposive, QUOT quotation, SBST substantivizer, SG singular, SRSS superessive, and SUG suggestive.

6. In fact, this is also the reason why I think (20) can be regarded as a genuine reason construction. One reviewer argues that (20) is a simple juxtaposition of two main clauses, but this assumption would lead to a different interpretation from the one actually associated with the structure. The link of the apprehensive mood to the agent of the main clause is crucial to obtain the reason interpretation, and this shows that the construction cannot be a simple juxtaposition of main clauses.

7. Role and Reference Grammar is somewhat different from the other two frameworks in that the basic distinction between interaction-related and description-related layers of organization is not part of the general architecture of the model. The distinction is implicitly present in several parts of the model, however, for instance in the treatment of operator categories like modality (see further in Verstraete 2001).

\section{References}

Amha, Azeb (2001). The Maale language. Unpublished doctoral dissertation, University of Leiden.

Bashir, Elena (1988). Topics in Kalasha syntax: an areal and typological perspective. Unpublished doctoral dissertation, University of Michigan.

Bhatia, Tej (1993). Punjabi: A Cognitive-Descriptive Grammar. London: Routledge.

Bolkestein, Machtelt (1991). Causally related predications and the choice between parataxis and hypotaxis in Latin. In New Studies in Latin Linguistics, Roger Coleman (ed.), 427451. Amsterdam: John Benjamins.

Bossong, Georg (1979). Typologie der Hypotaxe. Folia Linguistica 13, 33-54.

Butler, Christopher S. (2003). Structure and Function. A Guide to Three Major StructuralFunctional Theories, 2 vols. Amsterdam: John Benjamins. 
Chelliah, Shobhana (1997). A Grammar of Meithei. Berlin and New York: Mouton de Gruyter.

Cristofaro, Sonia (2003). Subordination. Oxford: Oxford University Press.

Dik, Simon (1997). The Theory of Functional Grammar: Part 2. Kees Hengeveld (ed.). Berlin and New York: Mouton de Gruyter.

Dik, Simon; Hengeveld, Kees; Vester, Elseline; and Vet, Co (1990). The hierarchical structure of the clause and the typology of adverbial satellites. In Layers and Levels of Representation in Language Theory: A Functional View, Jan Nuyts, A. Machtelt Bolkestein, and Co Vet (eds.), 25-70. Amsterdam: John Benjamins.

Dik, Simon and Hengeveld, Kees (1991). The hierarchical structure of the clause and the typology of perception verb complements. Linguistics 29, 231-259.

Evans, Nicholas (2003). A Pan-Dialectal Grammar of Bininj-Gun-Wok: Mayali, Kunwinjku and Kune. Canberra: Pacific Linguistics.

Everett, Dan and Kern, Barbara (1997). Wari'. The Languages of Pacaas Novos of Western Brazil. London: Routledge.

Foley, William (1991). The Yimas Language of New Guinea. Stanford: Stanford University Press.

Foley, William and Van Valin, Robert (1984). Functional Syntax and Universal Grammar. Cambridge: Cambridge University Press.

Frajzyngier, Zygmunt (1991). The de dicto domain in language. In Approaches to Grammaticalization: Volume 1, Elizabeth Traugott and Bernd Heine (eds.), 219-251. Amsterdam: John Benjamins.

Frajzyngier, Zygmunt (1996). Grammaticalization of the Complex Sentence. A Case Study in Chadic. Amsterdam: John Benjamins.

Frajzyngier, Zygmunt (2001). A Grammar of Lele. Stanford: CSLI.

François, Alexandre (2001). Contraintes de structures et liberté dans l'organisation du discours. Une description du mwotlap, langue océanienne du Vanuatu. Unpublished doctoral dissertation, Université Paris-IV Sorbonne.

Givón, Talmy (1994). Irrealis and the subjunctive. Studies in Language 18, 265-337.

Güldemann, Tom (2002). When 'say' is not say. The functional versatility of the Bantu quotative. In Reported Discourse, Tom Güldemann and Manfred von Roncador (eds.), 253287. Amsterdam: John Benjamins.

Halliday, Michael (1985). An Introduction to Functional Grammar. London: Arnold.

Halliday, Michael and Matthiessen, Christian (2004). An Introduction to Functional Grammar, 3rd ed. London: Arnold.

Haspelmath, Martin (1993). A Grammar of Lezgian. Berlin and New York: Mouton de Gruyter.

Haiman, John (1980). Hua: A Papuan Language of the Eastern Highlands of New Guinea. Amsterdam: John Benjamins.

Heath, Jeffrey (1999). A Grammar of Koyra Chiini. Berlin and New York: Mouton de Gruyter.

Hengeveld, Kees (1989). Layers and operators in functional grammar. Journal of Linguistics $25,127-157$.

Hengeveld, Kees (1996). The internal structure of adverbial clauses. In Complex Structures: A Functionalist Perspective, Betty Devriendt, Louis Goossens and Johan van der Auwera (eds.), 119-147. Berlin and New York: Mouton de Gruyter.

Hengeveld, Kees (1998). Adverbial clauses in the languages of Europe. In Adverbial Constructions in the Languages of Europe, Johan van der Auwera (ed.), 335-419. Berlin and New York: Mouton de Gruyter.

Hercus, Louise (1994). A Grammar of the Arabana-Wangkangurru Language, Lake Eyre Basin, South Australia. Canberra: Pacific Linguistics. 
Hewitt, George (1987). The Typology of Subordination in Georgian and Abkhaz. Berlin and New York: Mouton de Gruyter.

Ikoro, Suano (1996). The Kana Language. Leiden: CNWS.

Jaggar, Philip (2001). Hausa. Amsterdam: John Benjamins.

Jones, Charles (1985). Agent, patient, and control in purpose clauses. Chicago Linguistic Society 21, 105-119.

Karttunen, Lauri (1973). Presuppositions of compound sentences. Linguistic Inquiry 4, 169193.

Keenan, Edward (1971). Two kinds of presupposition in natural language. In Studies in Linguistic Semantics, Charles Fillmore and Terence Langendoen (eds.), 44-52. New York: Holt, Rinehart, and Winston.

Kempson, Ruth (1975). Presupposition and the Delimitation of Semantics. Cambridge: Cambridge University Press.

Lakoff, Robin (1968). Abstract Syntax and Latin Complementation. Cambridge, MA: MIT Press.

Levinson, Stephen (1983). Pragmatics. Cambridge: Cambridge University Press.

Loughnane, Robyn (2003). A discussion of mood, modality and related categories in Golin. Unpublished manuscript, University of Melbourne.

Lowe, Ivan (1987). Two ways of looking at causes and reasons. In Grammar in the Construction of Texts, James Monaghan (ed.), 37-46. London: Pinter.

McGregor, William (1997). Semiotic Grammar. Oxford: Oxford University Press.

Morse, Nancy and Maxwell, Michael (1999). Cubeo Grammar. Arlington, VA: Summer Institute of Linguistics.

Nichols, Johanna (1988). Nominalization and assertion in scientific Russian prose. In Clause Combining in Grammar and Discourse, John Haiman and Sandra Thompson (eds.), 399428. Amsterdam: John Benjamins.

Nordlinger, Rachel (1998). A Grammar of Wambaya, Northern Territory (Australia). Canberra: Pacific Linguistics.

Palmer, Frank (1987). The typology of subordination: results, actual and potential. Transactions of the Philological Society, 90-109.

Palmer, Frank (2001). Mood and Modality, 2nd ed. Cambridge: Cambridge University Press.

Pandharipande, Rajeshwari (1997). Marathi. London: Routledge.

Reesink, Ger (1987). Structures and their Functions in Usan. A Papuan Language of Papua New Guinea. Amsterdam: John Benjamins.

Reesink, Ger (1999). A Grammar of Hatam. Canberra: Pacific Linguistics.

Rice, Keren (1989). A Grammar of Slave. Berlin and New York: Mouton de Gruyter.

Rice, Keren (1985). The optative and *s- and *n-conjugation marking in Slave. International Journal of American Linguistics 51, 282-301.

Rose, Françoise (2003). Morphosyntaxe de l'Emerillon. Langue tupi-guarani de Guyane française. Unpublished doctoral dissertation, University of Lyon.

Ross, John (1970). On declarative sentences. In Readings in English Transformational Grammar, Roderick Jacobs and Peter Rosenbaum (eds.), 222-272. Waltham: Ginn.

Saxena, Anju (1995). Unidirectional grammaticalization: diachronic and cross-linguistic evidence. Sprachtypologie und Unversalienforschung 48, 350-372.

Soukka, Maria (2000). A Descriptive Grammar of Noon. Munich: Lincom.

Sridhar, Shikaripur (1990). Kannada. London: Routledge.

Stirling, Lesley (1993). Switch-Reference and Discourse Representation. Cambridge: Cambridge University Press. 
Thompson, Sandra and Longacre, Robert (1985). Adverbial clauses. In Language Typology and Syntactic Description. Volume 2: Complex Constructions, Timothy Shopen (ed.), 171234. Cambridge: Cambridge University Press.

Van Valin, Robert and LaPolla, Randy (1997). Syntax: Structure, Meaning and Function. Cambridge: Cambridge University Press.

Verstraete, Jean-Christophe (1998). A semiotic model for the description of levels in conjunction. Functions of Language 5, 179-211.

Verstraete, Jean-Christophe (2001). Subjective and objective modality. Journal of Pragmatics 33, 1505-1528.

Verstraete, Jean-Christophe (2003). Preverbal positions in three Germanic languages: The role of scope as a functional principle. Languages in Contrast 4, 105-136.

Verstraete, Jean-Christophe (2004). Initial and final position for adverbial clauses in English: the constructional basis of the discursive and syntactic differences. Linguistics 42, 819853.

Verstraete, Jean-Christophe (2005). Two types of coordination in clause combining. Lingua $115,611-626$.

Verstraete, Jean-Christophe (forthcoming). The role of mood marking in complex sentences: a case study of Australian languages. To appear in Word.

Weber, David (1974). A Grammar of Huallaga Quechua. Berkeley, CA: University of California Press.

Wilkins, David (1989). Mparntwe Arrernte (Aranda): studies in the structure and semantics of grammar. Unpublished doctoral dissertation, Australian National University.

Winter, Eugene (1982). Towards a Contextual Grammar of English. The Clause and its Place in the Definition of the Sentence. London: Allen and Unwin. 